\title{
Reinterpretando Vazios Dialetológicos no Norte do Brasil
}

\author{
Marilucia Barros de OLIVEIRA* \\ Celiane Sousa COSTA** \\ Flávia Helena da Silva PAZ***
}

* Mestre em Letras pela Universidade Federal do Pará (2002). Doutora em Letras e Linguística pela Universidade Federal de Alagoas (2007). Docente da Universidade Federal do Pará. Contato: mariluci@ufpa.br.

** Mestre em Estudos Linguísticos pela Universidade Federal do Pará (2009). Doutoranda em Letras na Universidade Federal do Pará. Docente da Universidade Federal do Oeste do Pará. Contato: celucosta@gmail.com.

*** Mestre em Estudos Linguísticos pela Universidade Federal do Pará (2013). Doutoranda em Letras na Universidade Federal do Pará. Contato: dapazhelena@yahoo.com.br.

\section{Resumo:}

No presente artigo, pretendemos apresentar reflexões sobre questões que não são facilmente respondidas quando da aplicação do Questionário Fonético-Fonológico (QFF) e do Questionário Semântico-Lexical (QSL). Esses questionários integram a metodologia do Projeto Atlas Linguístico do Brasil (ALiB), projeto de orientação dialetológica que tem como objetivo descrever e mapear a variação e diversidade linguística do Português Brasileiro. Vamos nos ater especificamente à seleção e análise de questões usadas para coletar dados cujo uso apresenta dificuldade quando dessa coleta. Limitamo-nos à apresentação, reflexão e discussão das questões 32 e 41 do questionário aplicado pelo ALiB. A questão 32 integra o QFF e tem como objetivo obter a forma 'abóbora'. Já a questão 41 faz parte do QSL e tem como uma das variantes esperadas 'camomila'. A hipótese principal na explicação dos fatos é de que há pressão dos fatores sociais, não apenas dos fatores clássicos, mas também da avaliação social das formas linguísticas, bem como do fator histórico-cultural, parte integrante da realidade linguísticocultural de qualquer comunidade investigada.

\section{Palavras-chave:}

Dialetologia. Vazio dialetológico. Representação cartográfica.

Signum: Estudos da Linguagem, Londrina, v. 21, n. 1, p. 12-31, abr. 2018 


\section{Reinterpretando Vazios Dialetológicos no Norte do Brasil}

Marilucia Barros de Oliveira; Celiane Sousa Costa; Flávia Helena da Silva Paz

\section{INTRODUÇÃo}

A pesquisa empírica implica necessariamente o trabalho com dados. Quando da adoção de um modelo dessa natureza, diferentemente do que pregavam os modelos mentalistas, os dados obtidos apresentam primazia e a teorização é feita a posteriori com base nas evidências fornecidas pelos dados. Nessa perspectiva, os dados podem apresentar evidências linguísticas que só podem ser obtidas quando se leva em consideração a língua em uso. Entretanto, cabe ressaltar que, para que o pesquisador tenha em mãos um bom corpus para análise, a coleta de dados precisa ser planejada. Deve-se considerar, entre outros, instrumentos e critérios que estejam em consonância com o que se pretende investigar. Essa não é uma tarefa fácil. Portanto, os instrumentos de coleta de dados assumem uma status especial na pesquisa que adotam esse modelo.

No Brasil, atualmente, é alto o número de pesquisas que se utilizam de dados empíricos para investigação linguística. O avanço dos trabalhos sobre variação linguística, com destaque para a Sociolinguística e Dialetologia, estão ligados a essa produtividade. São vários os instrumentos de pesquisa adotados por sociolinguistas e dialetólogos. A Dialetologia tem se concentrado mais no uso de questionários. No Brasil, eles têm sido costumeiramente usados para a construção de atlas linguísticos. Destacamos, nesse contexto, o Projeto Atlas Linguístico do Brasil (ALiB), cuja coleta de dados é também feita por meio de questionários, mas não apenas por meio deles. É sobre as dificuldades de recolha de dados quando da aplicação de algumas questões do Questionário Fonético-Fonológico (QFF) e do Questionário Semântico-Lexical (QSL) usados pelo ALiB que se voltará nossa análise. Pretendemos apontar, discutir algumas causas da "não resposta", analisar as reformulações aplicadas às questões originais para obtenção das respostas e os impactos que decorrem dessas reformulações. A escolha do ALiB se baseia no fato de os questionários usados pelo projeto terem a árdua tarefa de dar conta da diversidade linguística e cultural do país. Dizemos também cultural pois, se uma dada pergunta não estiver em consonância com o conhecimento, a cultura de uma determinada região, por exemplo, a pergunta pode não ser respondida ou ser respondida com dificuldade, tendo-se, algumas vezes, de recorrer a reformulações. Isso traz impactos para os resultados a serem cartografados e a necessidade de alguns detalhamentos úteis à compreensão dos resultados, como veremos mais adiante.

Como instrumento de coleta de informações linguísticas e sociais no campo da Dialetologia brasileira, os questionários do ALiB podem evidenciar diferenças linguísticas regionais, a partir de questões de toponímia antro-cultural e linguísticas propriamente. 
Contudo, há formulações de questões não favorecedoras de usos correntes que podem efetivamente representar particularidades regionais (ou regionalismos), o que é natural, dada a extensão do referido projeto.

Em 2007, quando realizávamos coleta de dados para o ALiB na condição de pesquisador auxiliar, vivenciamos uma situação que nos fez refletir sobre como o conhecimento da cultura local é importante para a elaboração de questões que integram um questionário e para sua reelaboração, quando essas perguntas não são facilmente respondidas, seja por apresentarem alguma dificuldade em sua formulação ou por seu conteúdo não integrar o conhecimento dos falantes que são entrevistados. É sobre questões dessa natureza que vamos nos ater.

Voltando à experiência vivenciada, lembramos que a situação referia-se à questão 32 do QFF: ... a auilo que dá no chão, grande (mímica), com uma casca grossa vermelho-amarelada por dentro e que se cozinha para comer, fazer doce? (COMITÊ NACIONAL DO PROJETO ALiB, 2001, p. 9). A resposta esperada, 'abóbora', não era respondida pelo entrevistado. Assistíamos e víamos que não seria facilmente respondida, pois havia informações na pergunta que não faziam parte da cultura local ou faltava alguma informação na questão que pudesse ativar na memória aquilo que estava sendo descrito, algo mais específico da cultura alimentar do Norte do país. Mesmo já tendo usado o referido questionário, ainda não tínhamos nos dado conta disso. Pedimos que a entrevistadora fizesse uma pausa e incluísse na pergunta a seguinte informação: ... vocês costumam colocar aqui no cozidão. A resposta foi imediata. Esse fato, dentre outras motivações, estimulou-nos a investir na presente pesquisa, tomando por base os dados das capitais do Norte do Brasil.

Nossa análise vai se ater às perguntas feitas, às reformulações dessas perguntas, às respostas apresentadas à formulação e à reformulação das questões e aos tipos de respostas apresentadas. Apresentaremos, ainda, considerações sobre alguns aspectos que foram ignorados nas perguntas, ou mesmo em sua reformulação, levantando questões referentes aos impactos que isso tem na apresentação dos resultados e na apresentação das cartas. Por fim, reiteraremos e/ou apresentaremos algumas reflexões, sugestões que podem contribuir para que as respostas sejam obtidas de forma menos trabalhosa, tanto para o inquiridor quanto para o entrevistado.

\section{Metodologia}

A análise dos dados do presente estudo tomou como base as perguntas feitas pelos inquiridores e as respostas apresentadas pelos falantes de seis capitais da Região Norte. Elas foram escolhidas com base nas experiências acumuladas na pesquisa de campo e no manuseio dos dados para o estudo da variação fonética e diversidade lexical dessa região. Como já foi dito, compuseram o corpus as perguntas e respostas referentes às questões 32 e 41 dos questionários aplicados pelo Projeto Atlas Linguístico do Brasil (ALiB). A questão 32 integra o QFF e a questão 41 faz parte do QSL. Isso tem uma implicação importante e demanda a 
apresentação do entendimento que temos de resposta esperada, termo comumente usado entre os dialetólogos.

As respostas previstas no QFF devem ser exatamente as que aparecem como resposta esperada no referido questionário, pois elas serão alvo de análise fonético-fonológica. Nelas se encontram o contexto fonético-fonológico e a variável que se pretende analisar. Nesse caso, aplica-se bem o termo resposta esperada. Já as questões que integram o QSL podem apresentar várias possibilidades de resposta, já que se quer identificar, descrever, mapear a diversidade lexical no Brasil. Assim um número alto de variantes, de respostas é muito bemvindo. O questionário aponta uma das possibilidades de ocorrência, como é o caso de 'camomila' para a questão 41 do QSL. Trata-se de objetivos diferentes e, portanto, procedimentos diferenciados para a coleta de dados.

Podemos dizer que a interação entre os envolvidos nas entrevistas também foi objeto de nossa análise, assim como as respostas que decorreram de pergunta tal qual prevista no questionário ou de sua reformulação.

As entrevistas levaram em consideração seis capitais da Região Norte, a saber: Belém, Boa Vista, Macapá, Manaus, Porto Velho e Rio Branco ${ }^{1}$. Os dados analisados correspondem a 48 entrevistados no total; sendo oito colaboradores por capital, estratificados conforme a idade (18 a 30 anos e 50 a 65 anos), sexo (feminino e masculino) e escolaridade (alfabetizados até a $4^{\mathrm{a}}$ série do Ensino Fundamental e com curso de Ensino Superior).

Primeiramente, foram transcritas grafematicamente todas as entrevistas realizadas nas capitais referidas. Em seguida, procedemos à seleção e à escuta das entrevistas para avaliar aspectos relacionados às respostas das questões em estudo. Caberia saber se havia dificuldade na obtenção das respostas; para isso, tínhamos de identificar como as respostas foram obtidas, por meio de reformulação ou não. Também avaliamos a natureza das reformulações, o tipo de resposta obtida e as inserções responsáveis pelo (in)sucesso das reformulações. Assim, caracterizamos as perguntas e respostas como:
a) Pergunta sem reformulação;
b) Pergunta com reformulação;
c) Natureza da reformulação;
d) Sem resposta ${ }^{2}$;
e) Não resposta ${ }^{3}$.

Além disso, avaliamos aspectos quantitativos; relacionamos tipos de perguntas a tipos de resposta. Feitas essas avaliações, debruçamo-nos sobre as interlocuções entre o

\footnotetext{
${ }^{1}$ Não há dados coletados para Palmas.

${ }^{2}$ Quando o informante não responde ou diz que não sabe.

${ }^{3}$ Resposta que não corresponde ao conceito que está apresentado na questão. Isso nem sempre é fácil de definir. Em alguns casos, determinados conceitos correspondem a referentes distintos em espaços geográficos diferentes.
} 
entrevistado e o inquiridor, no sentido de apontar que aspectos contribuíram para que a pergunta fosse ou não respondida ou para que a resposta não fosse considerada válida. As informações coletadas foram analisadas do ponto de vista social, histórico e cultural. Em alguns casos, recorremos a dicionários para consulta relativa às definições e à etimologia das ocorrências.

Passemos à apresentação e discussão dos resultados.

\section{"FATALIDADES DA IMPOSIÇÃo DO REGIONAL"}

Iniciaremos nossa análise pela questão 32 do QFF. Nesse questionário, as perguntas são feitas com o objetivo de se obter palavras já previstas para análise específica de fenômenos fonético-fonológicos. O objetivo dessa questão é obter o item 'abóbora'. A finalidade é avaliar a variação linguística em proparoxítonas, mais especificamente nas postônicas não finais do vocábulo. Assim, é imperativo que a resposta do entrevistado seja a forma léxica indicada no questionário.

\section{O que vai no cozidão?}

A questão 32 do QFF tem como resposta esperada o item 'abóbora' e apresenta a seguinte formulação: "...aquilo que dá no chão, grande (mímica), com uma casca grossa vermelhoamarelada por dentro e que se cozinha para comer, fazer doce?" (COMITÊ NACIONAL DO PROJETO ALiB, 2001, p. 9). A dificuldade para obtenção de 'abóbora' levou a um alto número de perguntas com reformulações no corpus, com diferença significativa de frequência entre os dois tipos de perguntas. São 29 perguntas com reformulação (60,42\%), contra 16 perguntas sem reformulação (33,33\%), cujas informações da pergunta original do questionário do ALiB foram resguardadas pelo inquiridor. Esse resultado aponta, pelo menos, duas dificuldades: a primeira diz respeito à aquisição da variante que corresponde ao conceito apresentado na questão, o que discutiremos mais adiante. A segunda refere-se à obtenção da forma 'abóbora', já que, no Norte do país, o fruto é também chamado de jerimum.

Por se tratar de um fruto muito conhecido no Brasil, facilmente encontrado para aquisição e com potencial de aproveitamento completo na culinária, as alterações nas questões restringiram-se propriamente à inserção de informação com particularidades culturais, relativas à funcionalidade ('serve para...'), ativada na memória pelas expressões ‘cozidão' ou 'coloca na carne cozida'. A evidência da influência dessas expressões para obtenção da resposta esperada e de suas variantes pode se confirmar quando recorremos ao número de perguntas sem resposta (três únicas ocorrências); a ausência das informações mencionadas nas perguntas

\footnotetext{
${ }^{4}$ O título dessa seção retoma o texto de Rossi (1967) sobre "Dialectologia". Pareceu-nos muito adequado e aplicável ao presente estudo. Recomendamos a leitura.
} 
com alterações implicou na ausência total de ocorrências (seja da resposta esperada, seja de suas variantes). $O$ trecho a seguir, obtido numa entrevista em Rio Branco (Mulher, $2^{\mathrm{a}}$ faixa etária, Ensino Superior), exemplifica isso:

\section{Fragmento 1}

INQ.- E aquilo que dá no chão assim que é gran::de com co... com a casca gro::ssa meio vermelho amarelada por de::ntro, que faz do::ce, dá pa comê também na sala::da?

INF.- Dá no chão?

INQ.- É. Tem uns que são redon::dos assim, tem uns go::mos ou que são...

INF.- Ah me... éh::

INQ.- Dá pa fazê um doce gusto::so igual... eu num sei se vocês fazem doce aqui disso ou põe na caldera::da.

INF.- Eu nu... nã peraí (risos)

INQ.- Não, mas nu tem problema. Depois eu retomo.

A relevância do conhecimento de particularidades regionais na aplicação QFF se revelou também na tentativa inapropriada de extensão da funcionalidade do item 'abóbora' para um outro tipo de comida, realçado no Fragmento 1. Talvez por se tratar de um prato muito conhecido na Região Norte, peixe cozido com legumes, o inquiridor fez alusão a ele. Mas, na região, não se tem o costume de acrescentar abóbora nessa iguaria. Por isso, entendemos que a presença do item 'calderada' na pergunta tenha impossibilitado a obtenção de resposta. Diferentemente do exemplo a seguir, obtido numa entrevista em Porto Velho (Mulher, $1^{a}$ faixa etária, Ensino Superior), em que os itens 'cozido' e 'cozidão', que alcançam o referente 'carne cozida com legumes', favorecem uma resposta imediata, a resposta esperada e sua variante lexical.

\section{Fragmento 2}

INQ.- Como é que chama aquilo que dá no chã::o, gran::de, uma casca gro::ssa meio vermelho alaranjada por den::tro...

INF.- Melancia. Não...

INQ.- Usa pa fazê no cozido, cozidão.

INF.- Abóbora.

INQ.- É. I::sso tem outro nome por aqui?

INF.- Jerimum.

Um procedimento frequente na pesquisa dialetológica é persistir na questão e reformulá-la para obtenção do item esperado e das variantes. A persistência na questão 32 do QFF evidenciou não apenas o (re)conhecimento e/ou preferência por um dos itens, como também a avaliação social de ocorrências, além de ter revelado espaços sociais de uso (mercado, feira, zona rural) para cada item. Conforme se pode observar no exemplo a seguir, obtido de uma entrevista em Manaus (Mulher, $2^{a}$ faixa etária, Ensino Fundamental). 


\section{Fragmento 3}

INQ.- E aquilo que dá assim no chã::o, que é grande com uma casca grossa e por dentro ele é meio vermelho amarelado?

INF.- Abóbara.

INQ.- Aqui:: fa... éh:: tem outro nome pra ele?

INF.- Jurumu que a gente chama pra ele, jurumu né?

INQ.- É:: a senhora usa mais o que?

INF.- Éh:: aqui nós chamamo mais abóbara.

INQ.- É?

INF.- É abóbara.

INQ.- Não usa mais o jerimum por aqui?

INF.- Nã::o, mais é abóbara.

INQ.- Ah é?

INF.- Que a ente compra mais em supermercado né.

INQ.- Ahn

INF.- Aí compra mair é abóbara, que chama até:: de... tem até abobrinha né? aquela pequena...

INQ.- É.

INF.- E tem a grande.

INQ.- A grande faz do::ce.

INF.- Agora lá po po terreno o pessual uso mais como jerimu.

INQ.- Pra onde?

INF.- Chamo jerimu.

INQ.- Onde que chama mais jerimu?

INF.- Assim nas estrada quando a gente vai comprá.

INQ.- Ah::

INF.- Qu'eles grandão né?

INQ.- É.

INF.- Chamo jerimu.

INQ.- Na cidade então...

INF.- É abóbara.

Quando os entrevistados foram interrogados sobre a amplitude do uso para as respostas obtidas na questão 32 do QFF, houve o reconhecimento de 'abóbora' como mais usual entre os não nascidos no lugar e/ou como mais frequente no setor comercial em área urbana. Além disso, houve também o reconhecimento do item 'jerimum' como mais comum entre os nascidos no local. Tais respostas nos fizeram pensar na pressão exercida pela influência tanto da mobilidade de usuários quanto de uma suposta padronização estabelecida pela 'lei' de mercado, isto porque há coocorrência dos itens com diferenças de formalidade apontadas pelos próprios entrevistados. Uma variante parece ser mais formal em função de seu emprego em estabelecimentos comerciais e outra variante parece ser mais informal em 
função de seu uso geralmente em ambientes mais familiar e não urbano. Vejamos o trecho a seguir, obtido de uma entrevista em Macapá (Mulher, $1^{a}$ faixa etária, Ensino Fundamental).

\section{Fragmento 4}

INQ.- Como é que chama aquilo que dá no chão, que é gran::de com uma casca grossa vermelho-amarelada por dentro que se cozinha pra comer::... faz o cozidão ...come com carne... faz a carne e põe os pedaços também?

INF.- Não é jerimum?

INQ.- Isso.

INF.- Abóbora, né? Que vocês chamo, né? (risos)

INQ.- É (riso)

INF.- Tem muita gente que chama abóbora. Nós chama jerimum aqui, né?

INQ.- Quem é que chama abóbora?

INF.- Muita gente. Muita gente chama de abóbora. Mas o pessoal pr'aí pra fora (risos), aí nós aqui é mais jerimum.

INQ.- É:.... É tudo de um tipo jerimum?

INF.- É

INQ.- Num tem diferença?

INF.- Não, tem uns mais vermelhinho, né? tem uns pouco amarelo, os vermelhinho que é mais gostoso, que é mais doce.

Além da avaliação do uso de formas marcadas com diferenças de formalidade, a evidência do tipo de situação sociolinguística para os itens em questão ${ }^{5}$ pode ser reiterada pelo fato de a maioria dos entrevistados mencionar os dois itens. Ao todo, são 23 ocorrências (47,92\%) para ‘jerimum' e 22 (45,83\%) para 'abóbora'. Assim, não podemos afirmar que há predominância de um desses itens na Região Norte, em função da sensível diferença entre o total de respostas para 'jerimum' e para 'abóbora'.

Como a natureza do QFF é hermética para o léxico, ou seja, o item esperado precisa ser necessariamente obtido, pois é nele que se encontra o contexto fonético-fonológico para análise, fica clara a necessidade de mudança na maneira de formular a pergunta ou orientação no sentido de que os inquiridores lancem mão do recurso usado nas reformulações para obter a resposta esperada.

Curioso notar que, além do esforço empreendido para obter a resposta para a questão 32 do QFF, o inquiridor precisa investir na aquisição da resposta esperada, que não pode ser

\footnotetext{
${ }^{5}$ Entendemos que a configuração sociolinguística nas capitais do Norte para a questão 32 do QFF aponta para um certo tipo de 'diglossia', em que há uma separação aparente entre as variantes alternativas com função social distinta. Para confirmar ou refutar esta evidência, seria pertinente um estudo mais horizontal sobre este item nas capitais e em cidades do interior na Região Norte.
} 
substituída por uma variante lexical pelos motivos já explicitados. Assim, apesar de ter usado as expressões que acionaram a memória para a obtenção de resposta, é necessário envidar esforços para a obtenção de ‘abóbora' e não 'jerimum'. Note-se que, tanto na pergunta sem quanto na com reformulação, 'jerimum' foi, em termos percentuais, o item que apareceu como primeira resposta, o que caracteriza mais uma complexidade na aquisição de itens para o QFF (Gráfico 1).

Gráfico 1 - Relação entre tipos de pergunta e respostas (QFF 32)

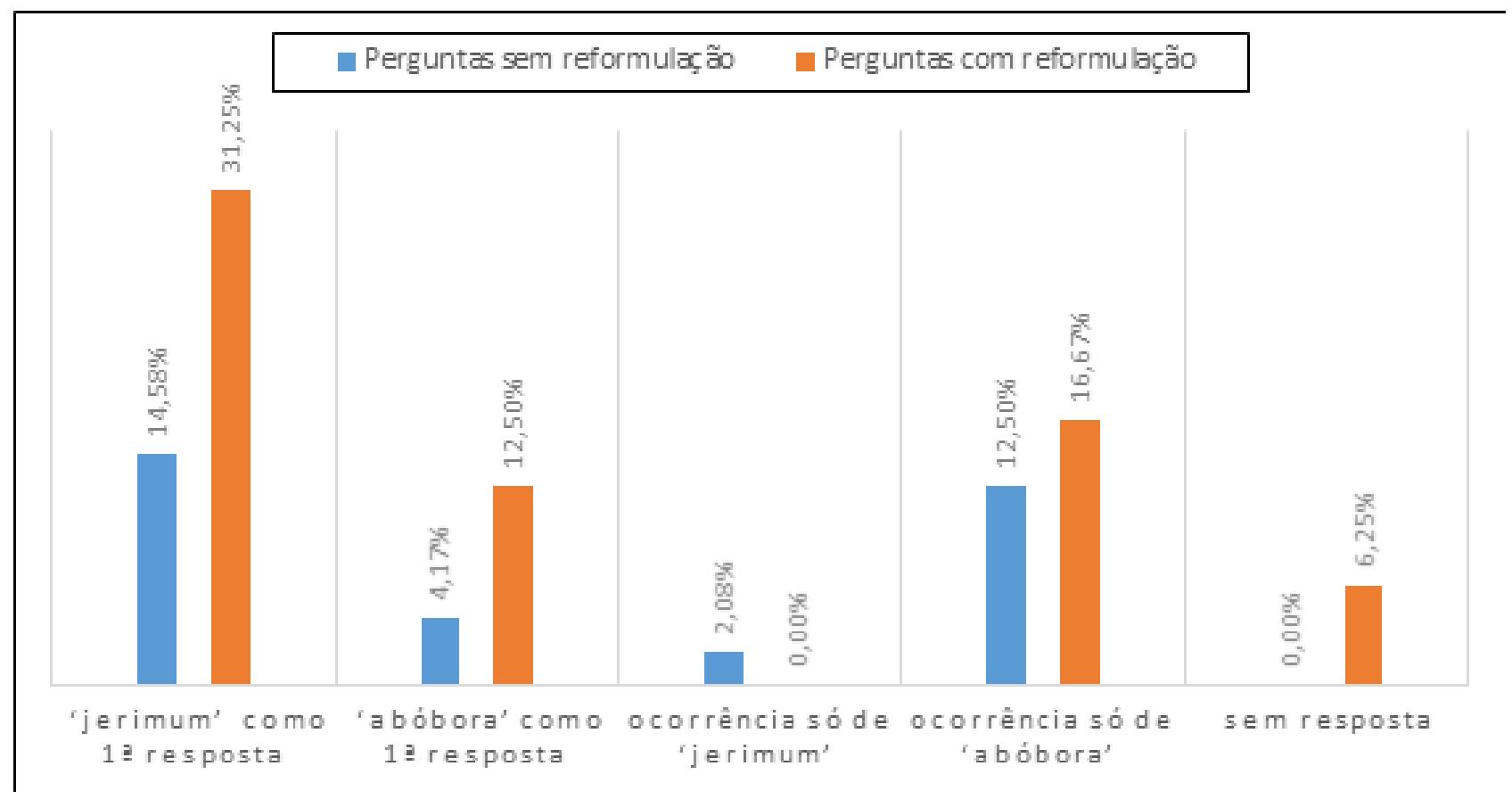

Fonte: Os próprios autores.

Essa dificuldade ainda se expressa na aquisição de apenas 'jerimum' como resposta e nos casos sem resposta, o que soma, ao todo, $8,33 \%$.

Ressaltamos que o fator escolaridade parece não ter interferido no estabelecimento dessas ocorrências, já que 'jerimum', por supostamente ser o item com traços de regionalidade maior, esteve presente nas respostas tanto de pessoas com o Ensino Fundamental quanto nas de Superior. Da mesma forma, a ocorrência só de 'abóbora' não se mostrou influenciada por esse fator.

É prática na coleta de dados do projeto ALiB que, ao final da aplicação do questionário, retomem-se as perguntas que não foram respondidas, o que denominamos, aqui, de repergunta. Ao analisarmos as reperguntas da questão 32 do QFF (4 reperguntas ao todo, perfazendo um percentual de 8,33\%), constatamos que em nenhuma delas os inquiridores adotaram a estratégia de reformulação de modo a inserir alguma informação 
com particularidades culturais relativas à funcionalidade do fruto, daí a dificuldade na obtenção das respostas na refacção da pergunta. Tal fato levou a sugerências do inquiridor e à resposta esperada com um certo grau de incerteza.

Como vimos, além dos tipos de pergunta, sem reformulação e com reformulação, as perguntas refeitas ao final do questionário também apontaram fortemente para a relevância do conhecimento cultural via particularidades regionais da culinária no Norte na apreensão de dados, incluindo a resposta esperada.

As cartas linguísticas ${ }^{6}$, apresentadas a seguir, evidenciam a diferença referente ao número de respostas fornecidas pelos entrevistados em relação ao tipo de pergunta, sem ou com reformulação. A Figura 1 corresponde à cartografia dos itens obtidos antes de aplicada a reformulação da pergunta. A Figura 2 corresponde à representação de itens para perguntas com reformulações.

Figura 1 - Resultado correspondente às perguntas sem reformulação (QFF 32)

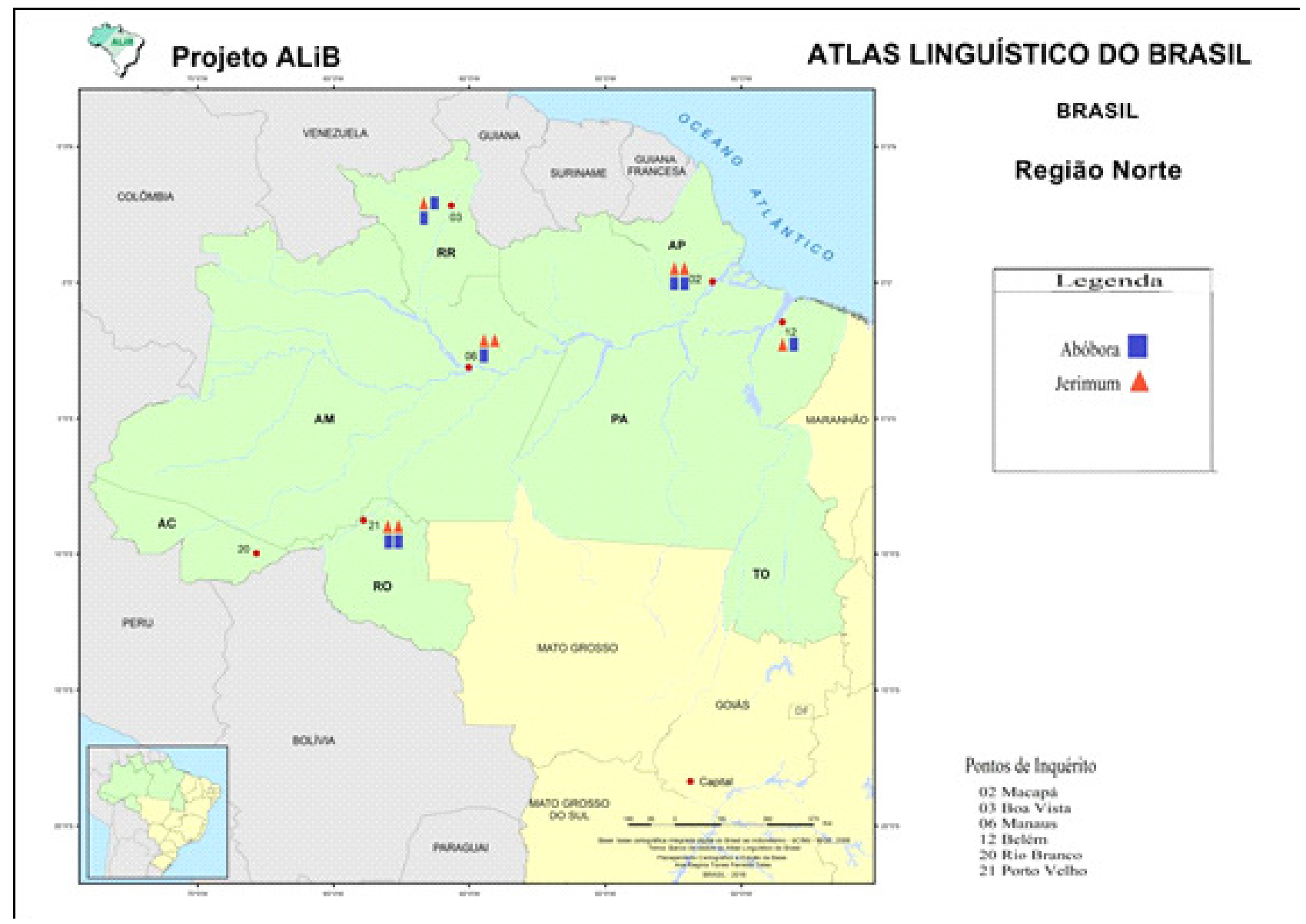

Fonte: Os próprios autores.

\footnotetext{
${ }^{6}$ Neste estudo, a disposição dos resultados nas cartas não prevê referência à estratificação social dos informantes: faixa etária, sexo e escolaridade.
} 
Figura 2 - Resultado correspondente às perguntas com reformulação (QFF 32)

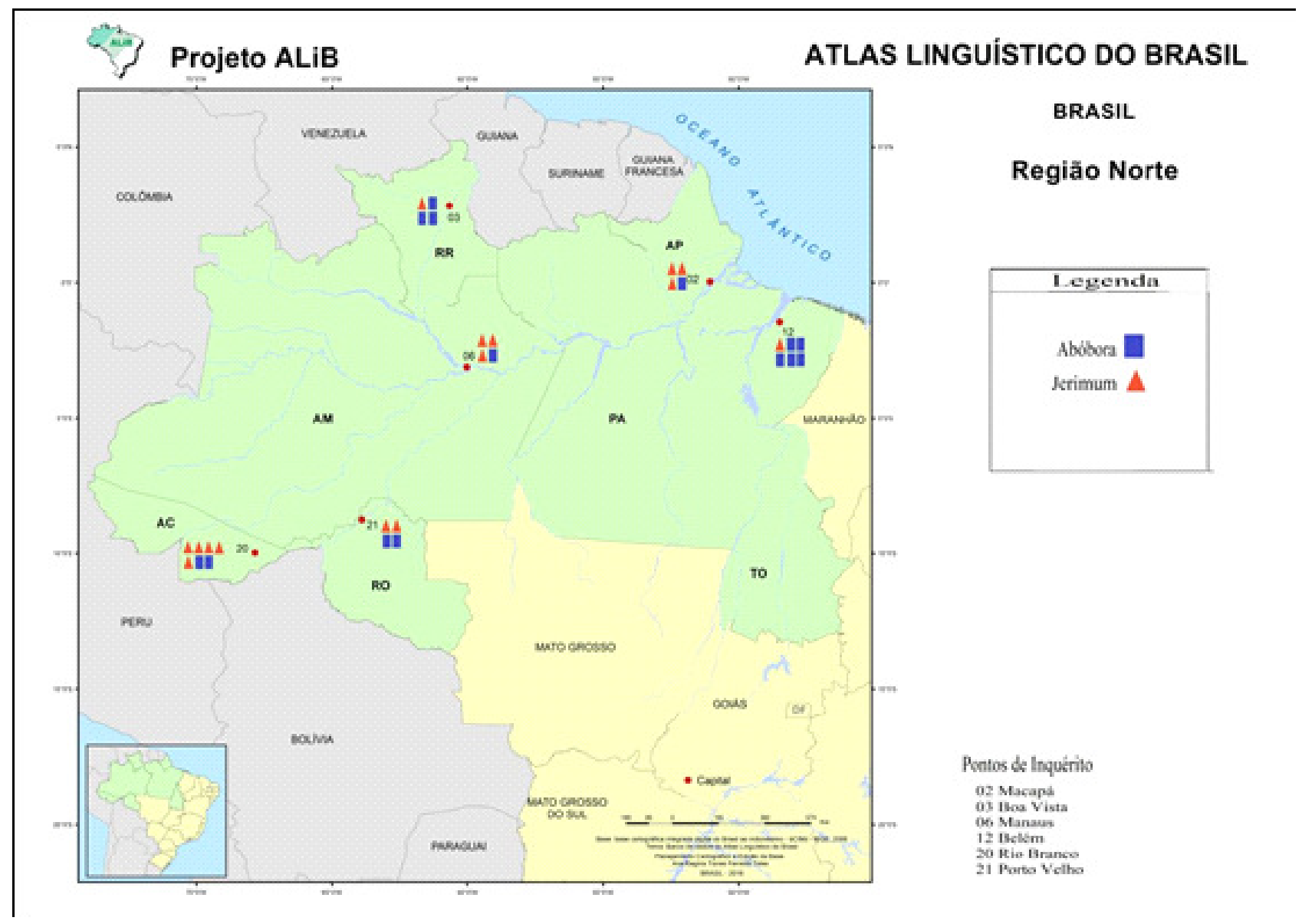

Fonte: Os próprios autores.

As cartas apresentadas evidenciam que as perguntas com reformulação implicaram mais respostas na coleta de dados e apontam para a necessidade de seu uso nesse caso.

\section{Chá pra quê?}

A questão 41 do QSL apresenta a seguinte formulação: “... umas florezinhas brancas com miolo amarelinho, ou floręinhas secas que se compram na farmácia ou no supermercado e servem para fazer um chá amarelinho, cheiroso, bom para dor de barriga de nenê/ bebê e até de adulto e também para acalmar? Mostrar" (COMITÊ NACIONAL DO PROJETO ALiB, 2001, p. 24). Uma das variantes esperadas, 'camomila', não foi facilmente respondida. A escuta da aplicação da pergunta mostra que o inquiridor teve de fazer grande esforço para a obtenção dessa resposta.

Os resultados para essa questão mostram diferenças significativas em relação aos resultados relativos à pergunta 32 do QFF, analisado na seção anterior. Essa pergunta obteve baixo índice de resposta antes da reformulação. Aqui, o índice de respostas é alto, mas, em muitos casos, elas não correspondem à forma esperada e suas variantes nem à descrição apresentada na pergunta. 'Camomila' apresentou frequência de 43,75\%, na soma da frequência 
só de 'camomila' e desse item com outras formas; ao passo que outras formas sem o item 'camomila' e os casos sem resposta apresentaram índice superior, perfazendo um total de 54,167\%, conforme Gráfico 2.

Gráfico 2 - Frequência de camomila e outras respostas (QSL 41)

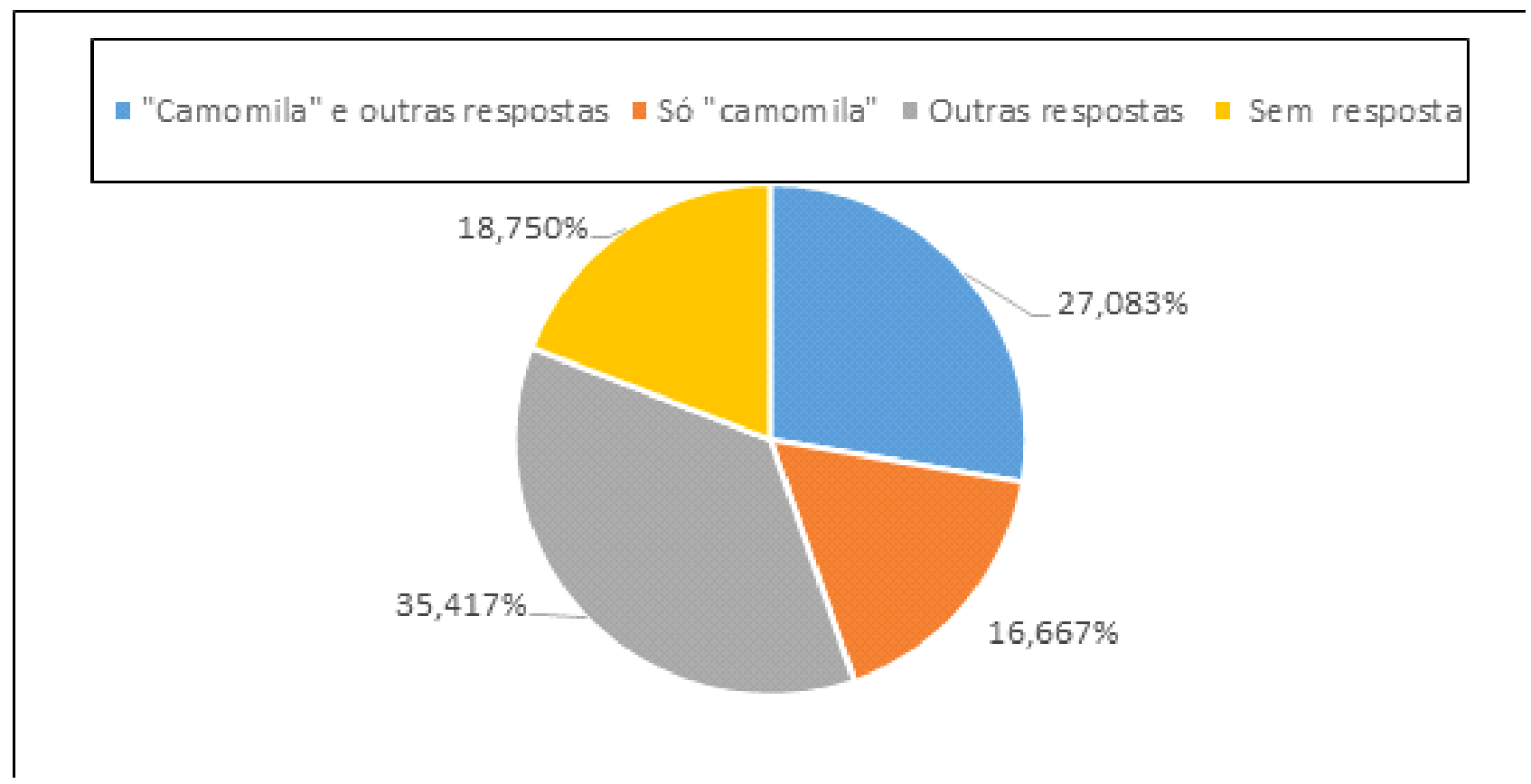

Fonte: Os próprios autores.

Em se tratando dos tipos de pergunta para o QSL 41, a maior frequência de ocorrência foi das perguntas sem reformulação, cujas informações básicas da questão original foram resguardadas pelo inquiridor, tais como: descrição da flor (matéria-prima do chá), lugar onde se compra a erva, a cor do chá, benefício medicinal (dor de barriga e calmante), acompanhadas geralmente pela apresentação do sachê contendo a erva seca. Em contrapartida, as alterações nas questões dizem respeito propriamente à inserção de indicações de uso da planta relacionadas à estética (clareador de cabelos), as quais não fazem parte da questão original. Ao todo, foram 43 questões sem reformulação $(89,584 \%)$ contra 4 questões com reformulação $(8,333 \%)$. Vale lembrar que $2,083 \%$ do total de entrevistas correspondem a perguntas não feitas.

Entendemos que nenhum dos dois tipos de questão (com ou sem reformulação) trouxe frequência significativa para afirmar sucesso na coleta de dados para um ou outro tipo de pergunta, já que houve apenas uma ligeira diferença entre o número de ocorrências nos casos em que as respostas obtidas limitaram-se apenas ao item 'camomila'. As questões sem reformulação, ou seja, aquelas com indicações terapêuticas medicinais, tiveram 5 ocorrências $(10,417 \%)$, ao passo que as questões com indicações estéticas, ou seja, aquelas com reformulações, tiveram 3 ocorrências (6,25\%). 
As perguntas sem reformulação cujas respostas incluem o item 'camomila' e outras respostas revelaram um certo tipo de 'ambiguidade' decorrente de questões pragmáticas em vez de flexibilidade léxica (ou melhor, variação lexical) comum ao tipo de questionário empregado, o QSL. Justamente porque nem o conhecimento supostamente patente da planta via conteúdo do sachê apresentado aos entrevistados e a descrição da flor, matériaprima do chá, foram suficientes para obtenção da resposta esperada. Ao contrário, a quantidade de ocorrência para os outros itens sem 'camomila' (35,417\%), cf. Gráfico 2, comprova a evidência da 'ambiguidade' pragmática. São mais de dez itens registrados para esta questão em oposição à parca ocorrência da "resposta esperada".

Como as plantas medicinais referidas pelos entrevistados são bem diferentes umas das outras, tanto em relação à planta em si quanto ao órgão utilizado para fazer chá, entendemos não haver itens alternativos de uso para 'camomila' na região, bem como não haver uma correlação entre a descrição da flor, visualização da erva no sachê e a indicação terapêutica referida na questão, por parte do entrevistado. Isso aponta tanto para o desconhecimento ou pouco uso da planta 'camomila' no Norte do Brasil, como também para a inevitabilidade de usos contextualmente específicos. Isso posto, entendemos que a função da planta via indicações terapêuticas medicinais possibilitou a variedade de itens com propriedades e benefícios aproximados ou equivalentes ao de 'camomila'. Das ervas mencionadas para dores na barriga e para acalmar, as mais recorrentes foram: erva cidreira (13 ocorrências), erva doce (13 ocorrências), bortelã (9 ocorrências), boldo (6 ocorrências). A exemplo dos destaques presentes no trecho a seguir, obtido de uma entrevista em Porto Velho (Homem, $2^{\mathrm{a}}$ faixa etária, Ensino Superior).

\section{Fragmento 5}

INQ.- Uma florzinha branca com o miolo amarelinho, uma florzinha seca que se compra na farmácia pra chá. Isso aqui (ININT) essa...

INF.- Flor branca.

INQ.- Essa (ININT)

INF.- Dex'ovê aqui.

INQ.- Que faz chá.

INF.- Confesso qu'eu num tô sentindo...

INQ.- Ela faz chá pa bebê, um chá amarelinho, que é bom pa dor de barriga também

INF.- É... num é sacaca não, não?

INQ.- Não, ela tem uma:: florzinha branca com miolo amarelinho a gente compra na farmácia...

INF.- Eu sei que tem... eu eu tomo muito chás, mas eu num sei se é:: eu num vi in natura assim, eu tomo chá de boldo, chá de sacaca, eh:.... tudo isso é bom pro estômago, eh:: picão. Agora essa flor aí... 
INQ.- Essa agora a gente já acha no supermercado também pra comprá em saquinho.

INF.- Uhn hum. Rapaz eu acho...

INQ.- O que que dá pra nenem aqui de chá?

INF.- Ah dá erva cidrera, eh:: capim santo,

INQ.- Ahn ham

INF.- Eh:: qual é otra? É:: hortelão, eh:: até folha de laranja...

INQ.- Tem uma que tem a florzinha bem:: amareli::nha, o chá fica bem:: amareli::nho. Aqui tem umas florzinhas dela (ININT)

INF.- É, não eu eu já sei de que é só qu'eu num tô lembrado o nome.

INQ.- Ahn

INF.- Eu tô... tô lembrando o nome não.

INQ.- Depois cê lembra. Se não lembrar também não tem problema.

As ocorrências destacadas no Fragmento 5 evidenciam o conhecimento de usos populares de plantas medicinais na região com benefícios equivalentes aos de camomila. Como o sintoma de dor de barriga pode ter causas variadas, talvez isso tenha favorecido a variedade de ocorrências: 'chá de boldo', 'erva cidreira', 'picão', 'capim santo', 'sacaca'. Todas essas plantas têm suas folhas aproveitadas sob forma empírica de chá. Notamos que a 'sacaca' é considerada por Tieppo (2007) como uma planta muito utilizada no norte do país sob forma de chá a partir de suas folhas e casca do caule, com indicações terapêuticas para o tratamento de diabetes, diarreia, malária, febre, distúrbios gastrintestinais, dentre outros benefícios. A camomila, por sua vez, é considerada também uma planta medicinal de uso caseiro, popularmente reconhecida por suas indicações terapêuticas medicinal e estética, bem como pela ingestão sob forma de chá. Contudo, o chá é preparado a partir das flores da planta. Essa informação é retomada pelo inquiridor três vezes no Fragmento 5, o que aponta para o não estabelecimento da correlação entre a descrição da flor da camomila, as indicações terapêuticas da planta referidas na questão e as plantas medicinais efetivamente mencionadas pelo entrevistado.

Se compararmos as ocorrências só de 'camomila' (16,667\%) com os outros itens mencionados sem 'camomila' (35,417\%), perceberemos que a diferença de 18,75\% entre os tipos de ocorrência é reveladora também da variedade de itens utilizados como respostas, em função da diversidade de plantas com propriedades medicinais comumente utilizadas na Região Norte, como evidencia o Fragmento 5.

O Fragmento 6, obtido de uma entrevista em Manaus (Mulher, $1^{\text {a }}$ faixa etária, Ensino Superior), apresenta um dos poucos exemplos empíricos de reconhecimento da planta. Só que esse reconhecimento é decorrente do cheiro e não da visualização das flores secas de camomila no sachê ou da descrição da flor. Isto porque a entrevistada afirma fazer uso frequente da camomila para fins medicinais e estéticos; neste último caso, para aproveitamento de benefícios estéticos/capilares. 


\section{Fragmento 6}

INQ.- Vo... será que você conhece isso aqui? Que você... lá a gente costuma fazê...

INF.- É, é oregano?

INQ.- Não. A gente costuma fazer chá pra...

INF.- Não. Camomila.

INQ.- pra nenem. Isso.

INF.- Camomila.

INQ.- Por que ninguém conhece isso aî? Já é a terceira... quarta pessoa, você foi a primeira pessoa que::...

INF.- Adoro chá de camomila.

INQ.- Ah::

INF.- Eu gosto de camomila e também uso camomila no cabelo.

INQ.- Ah::

INF.- O cheiro é comum pra mim...

INQ.- O que eu poderia perguntar pr'as pessoas eh:: por que...

INF.- Qual é o nome daquela... daquela planta que a gente passa no cabelo pra clareá (risos)

INQ.- Ah:: tá eu vou perguntar.

INF.- Ou então de que é aquele chá que se usa pra relaxar? Aí devem falá erva cidre::ra...

INQ.- Falaram erva cidrera, falaram erva doce, falaram::... daí até falei que lá a gente usa muito pra estômago sabe?

INF.- Ah::

INQ.- Então se você almoça e sente que num vai... fazê bem, você faz chá...

INF.- Fala do cabelo, que mulhé costuma comprá eh:: shampoo shampoo de camomila pra clariá o cabelo.

INQ.- Uhn hum é vo... porque lá nos temos outro nome pra camomila

INF.- Ah:: aqui não.

INQ.- Que é (maçanilha).

INF.- Não, esse eu nuca ouvi.

INQ.- É maçanilha. Então eu queria vê se tinha um outro nome, um nome diferente aqui...

INF.- Não tem. Camomila mesmo.

INQ.- Ahn ham

Importa mencionar que, apesar de a ocorrência de 'camomila' como resposta única (sem ocorrência de outras formas com a mesma função) ter sido usada apenas por pessoas com curso superior, 'camomila' foi registrada também nas respostas de pessoas tanto do ensino fundamental quanto superior. 
No Fragmento 6, constatamos que a visualização do sachê contendo a erva para o preparo do chá promoveu resposta com grau de incerteza: “É, é oregano?", desfeita pelo reconhecimento da camomila via olfato, segundo a própria entrevistada, após menção da função da planta: "Não. A gente costuma fažer chá pra...". Um outro exemplo de desconhecimento da planta camomila pode ser observado no Fragmento 7, a seguir. Para a entrevistada de Belém (Mulher, $1^{a}$ faixa etária, Ensino Fundamental), o conflito é estabelecido entre a descrição da flor e a função descrita na questão por conta do conhecimento que ela tem de uma flor muito semelhante (margarida), mas com funcionalidade diferente. Por serem a flor de margarida e a flor de camomila semelhantes, a função da planta, neste caso, foi fundamental para estabelecer dúvida na entrevistada. Margarida é uma planta ornamental; camomila, por sua vez, é medicinal.

\section{Fragmento 7}

INQ.- E::

INQ.- E:: com'é que chama umas florezinhas brancas com o miolo amareli::nho?... é:: que geralmente a gente compra na farmácia, serve pra fazê chá pra bebê ou serve pra fazê chá que serve como calmante.

INF.- Olha, eu num sei, porque... que eu sei flores brancas meio... centro amarelinho é a margarida, né?

INQ.- Uhm!

INF.- Num é isso, não faz chá, né? Essa otra, num se... tem a cidreira, né? Mas, a cidreira num...

INQ.- Conhece outra?

INF.- O chá da cidreira só é da folha num é flor.

INQ.- E chá pra acalmar a senhora conhece?

INF.- Ah, eu já sei é a flor de laranjeira, não!... Não é flor de laranjeira... também, esqueci.

INQ.- A senhora...

INF.- Tem de maracujá, mas...maracujá não é da flor...num se... camomila não é! Camomila, camomila não!

INQ.- Você... como é que é a camomila p'ra senhora?

INF.- Também não sei como é!

INQ.- A senhora nunca viu?

INF.- Ouço falá em chá de camomila, mas nunca vi.

INQ.- Ah, a senhora nunca viu!

INF.- Não conheço!

INQ.- Agora diga uma coisa esse chá de camomila a gente usa assim pra dor de barriga de nenê, pra acalmar, usa?

INF.- É!... Já ouvi falá assim pra acalmar, né? Só isso que eu sei.

INQ.- Hum tá! 
O Fragmento 7 deixa claro que a informante não (re)conhece camomila nem sua indicação para dor de barriga. No Norte, são outros os chás usados para esse fim.

Foi a dificuldade de apreensão de camomila e suas variantes que trouxe à tona a evidência de usos frequentes de outras plantas medicinais com a mesma função de camomila. Cabe ressaltar, também, que o fato de se mencionar 'camomila' não implicou necessariamente o (re)conhecimento ou uso da planta pelos entrevistados, como fica claro no Fragmento 8, obtido de uma entrevista em Boa Vista (Homem, $2^{a}$ faixa etária, Ensino Fundamental).

\section{Fragmento 8}

INQ.- Uma florzinha...é que faz chá...como o... pra criança...com miolinho amarelinha...Essa aqui por exemplo...essa aqui oh.

INF.- hum eu sei. Tem, a erva cidreira, tem a hortelã.

INQ.- E ess'aqui. E essa florzinha branca com essa miolinho amarelinho?

INF.- Essa num...

INQ.- As vezes a gente compra na farmácia pra fazê chá pra bebê.

INF.- (risos) eu tô querendo olhá o nome (risos)

INQ.- (risos)

INF.- Camomila, é?

INQ.- Ahn ham, Camomila!

INF.- Camomila! Eu nunca tinha visto, não. É a primeira vez que’u tô vendo

INQ.- Ah é?

INF.- É!

INQ.- Tem muito essa planta?

INF.- (Tosse) aqui não tem, não.

INQ.- Não.

INF.- Não aqui é muito difícil. Nunca vi, não!

INQ.- $A h !$

INF.- Eu já vi muitas planta medicinal, mas essa não!

A 'ambiguidade' pragmática revelada na questão 41 do QSL aponta, a nosso ver, para limites na apreensão da resposta esperada e de variantes, dado o presumível desconhecimento ou pouco uso da planta camomila no Norte do Brasil. Isso traz consequências para a representação cartográfica, produz vazios dialetológicos.

Se recorremos às perguntas a serem refeitas ao final do questionário, observamos uma prévia indicação de supostos vazios dialetológicos, por falta de obtenção da resposta 'camomila'. O total de reperguntas é de $54,167 \%$, o que significa que mais da metade do total de entrevistados deu outras respostas ou não respondeu, frente aos $43,75 \%$ de frequência para as respostas que incluem o item 'camomila'. A representação cartográfica que segue (Figura 3) manifesta o confronto entre presença versus ausência do item 'camomila'. 
Figura 3 - Distribuição diatópica de camomila

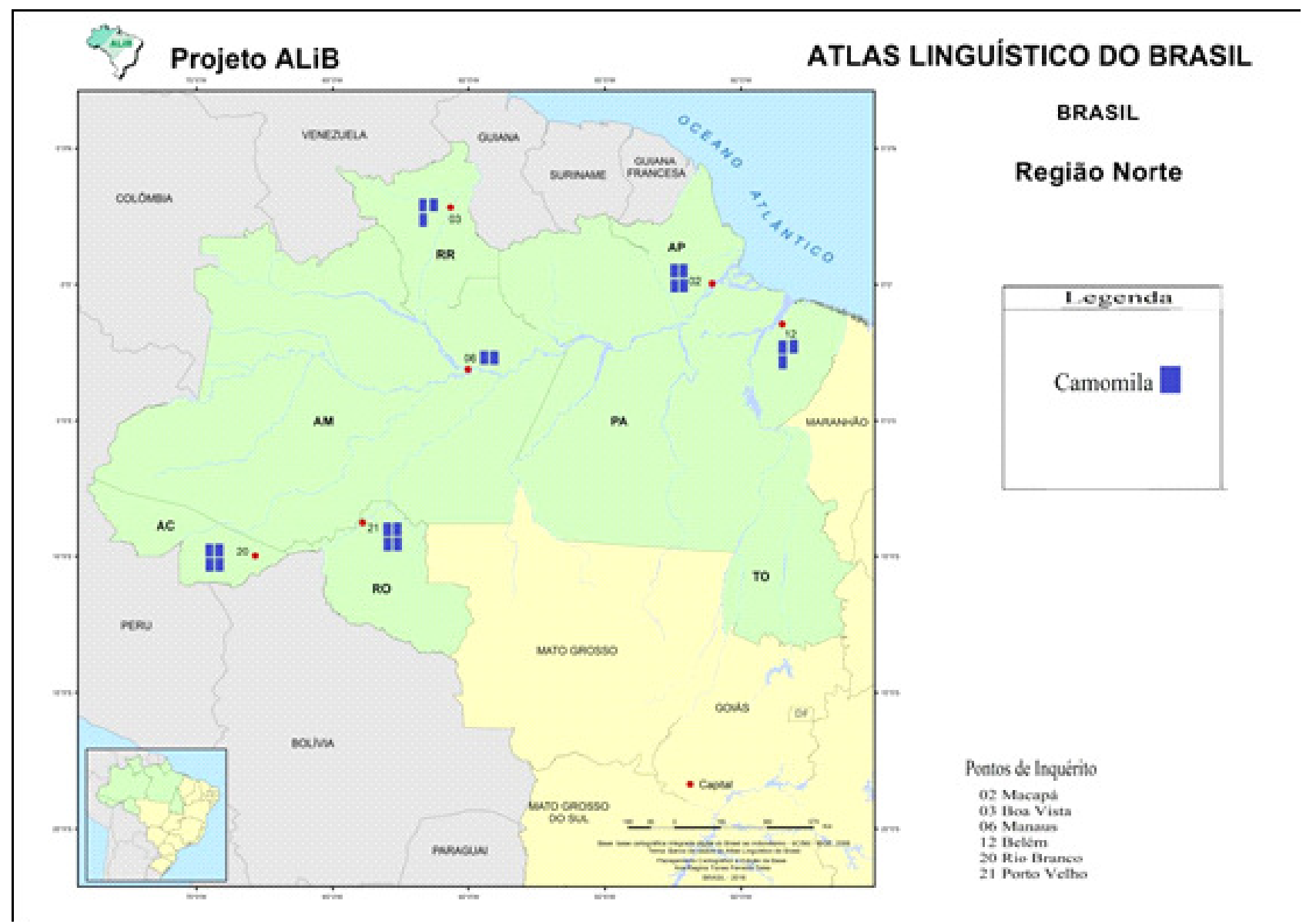

Fonte: Os próprios autores.

Ora, se o vazio dialetológico corresponde, grosso modo, à ausência de resposta prevista no QSL, que é "denunciador[a] de informações as mais diversas e pertinente para o confronto linguístico, do mesmo modo que o registro de uso" (CARDOSO, 2010, p. 15), é pertinente, então, que entendamos também a condição empírica da presença dessa resposta, já que a obtenção da resposta pode não pressupor efetivamente uso, como é o caso da questão 41.

A análise dessa pergunta e de suas respostas implicou o questionamento da existência de vazios em função do confronto dos dados a partir da presença versus ausência, bem como no questionamento da relação de usos dos itens efetivamente mencionados e entendidos como a resposta esperada, em face da pouca firmeza no conhecimento e usos da planta camomila.

Entendemos que o problema não incide propriamente nas questões com ou sem reformulação, diferentemente da pergunta 32 do QFF para o item 'abóbora', em que foi relevante a inserção de informação com particularidades culturais, ativadas na memória pelas expressões ‘cozidão’ ou ‘coloca na carne cozida'. Na pergunta 41 do QSL, é a variedade de plantas medicinais presentes no Brasil e seus inúmeros recursos terapêuticos, com usos 
que variam de uma região para outra, que desenham uma "realidade física com a qual o contexto cultural se identifica" (OLIVEIRA, 1997). É o que evidencia a representação cartográfica a seguir.

Figura 4 - Distribuição diatópica de 'Camomila' e outras plantas medicinais

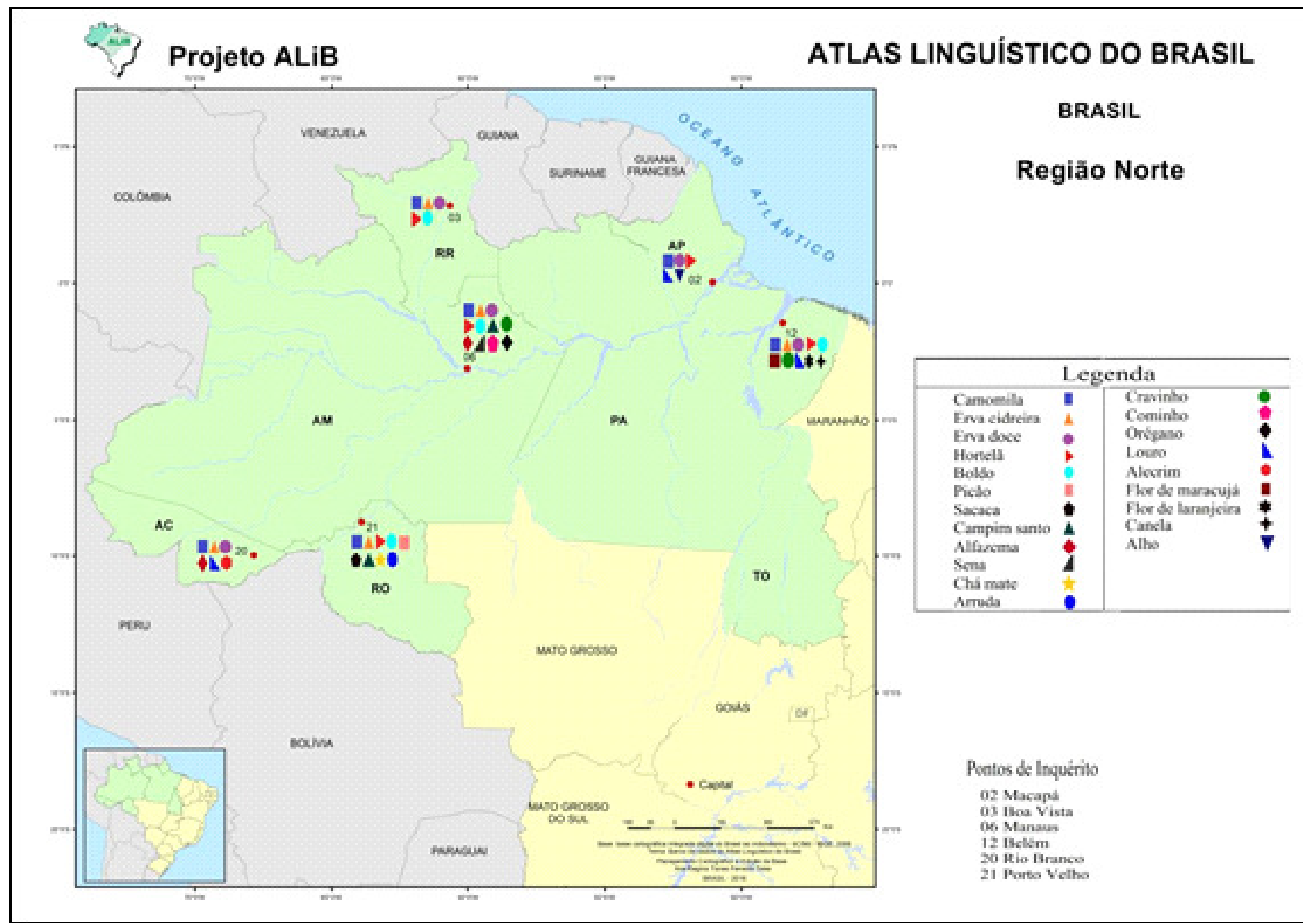

Fonte: Os próprios autores.

Com relação à camomila, podemos dizer que a aplicação da pergunta tal como apresentada no questionário possibilitou que soubéssemos que seu uso é restrito no Norte do Brasil, que seu reconhecimento pode se dar por meio da informação ligada a usos estético, capilares e que parece não ser usada como chá para fins medicinais ligados a dores abdominais na região. Como vimos, há outros chás usados para tal.

Nesse sentido, cabe usar a informação relativa ao uso estético se se quer saber onde se dá o uso de camomila e quais suas variantes, como sugere uma das informantes, ou manter as informações sobre benefícios medicinais se se quer saber que tipos de chás são usados na região para tal. O uso de imagens e cheiro são pouco indicados, já que a planta parece não ser comum na região.

Em suma, a dificuldade de obtenção de resposta em ambas as questões manifesta destacadamente um dos aspectos da pesquisa dialetológica enfatizada por Rossi (1967) em termos de "fatalidade das imposições do regional". 


\section{Considerações Finais}

Os resultados apresentados no presente artigo apontam, primeiramente, a necessidade da equipe multidisciplinar e de representantes de diversas regiões na elaboração de questionários que têm abrangência nacional. Mas isso não resolve de todo a problemática, porque sempre haverá aspectos que serão ignorados nesses instrumentos de coleta de dados. É durante a experiência em campo que são identificadas essas lacunas e que se coletam dados preciosos que nem se pretendia coletar, como vimos neste artigo, dada à gama de informação nova, não prevista, que surge durante coletas de dados dessa natureza. O impacto positivo da reformulação, o alcance do pragmático, do cultural e aprendizagens em campo devem ser levados em conta na (re)composição de questionários. De outro lado, cabe ressaltar que a forma como se apresentaram os questionários trouxe rica aprendizagem sobre variação lexical, diatópica e cultural das comunidades pesquisadas. As experiências vivenciadas pelos inquiridores e as alternativas encontradas para obtenção das respostas são, também, um ensinamento de como fazer pesquisa de campo tão desafiadora como a que se propôs fazer o ALiB. Parece necessário compartilhá-las, a fim de que as respostas sejam obtidas de forma menos sofrida. Investir na atualização desses questionários do projeto pode ser um novo desafio para o ALiB. Esperamos ter apresentado reflexões que contribuam para isso.

\section{REFERÊNCIAS}

CARDOSO, S. A. M. Geolinguística: tradição e modernidade. São Paulo: Parábola, 2010.

COMITÊ NACIONAL DO PROJETO ALIB. Atlas Lingüistico do Brasil: questionários 2001. Londrina: Ed. UEL, 2001.

OLIVEIRA, A. M. P. P. de. Regionalismos na flora do Brasil: um estudo no campo das plantas medicinais. Boletim da ABRALIN, ed. 21, jun. 1997.

ROSSI, N. A dialectologia. Alfa, v. 11, p. 89-115, 1967. Disponível em: <https://bit.ly/2rysDc6>. Acesso: 02 dez. 2016.

TIEPPO, M. Croton cajucara Benth (sacaca) uma planta da Amazônia: avaliação de seu potencial antioxidante. 2007. Dissertação (Mestrado em Medicina: Ciências Médicas) Universidade Federal do Rio Grande do Sul, Porto Alegre. Disponível em: <https://bit.ly/2G3ProD>. Acesso: 12 mar. 2017. 